\title{
Predicting delirium after a stroke
}

Stephen D J Makin, ${ }^{1}$ Joanna Wardlaw²

Clinicians treating patients with stroke will be familiar with delirium: a syndrome characterised by the rapid onset of disorganised thought, inattention and altered level of consciousness, with a characteristically fluctuant course. Limited data suggest that up to a quarter of patients with stroke admitted to hospital are affected at some point. ${ }^{1}$ In addition to being distressing for patients and carers, delirium doubles the risk of death and dependency. $^{2}$

If diagnosed correctly, delirium can be treated by searching for precipitating factors such as infection, altering predisposing factors such as medication and taking steps to reduce sensory impairment. ${ }^{3}$ However delirium is easily missed, partly due to its characteristic fluctuant course, which is especially concerning as if delirium is not detected on admission to hospital, then the risk of death may be increased eightfold. ${ }^{4}$

Patients with stroke are particularly likely to have one or more of the known risk factors for delirium, ${ }^{5}$ including cognitive impairment, visual impairment, infection and dehydration. Diagnosis may be more difficult as a change in mental state may be missed in a patient with aphasia or other speech disorder.

Oldenbeuving et $a l^{6}$ describe a tool to predict the risk of developing delirium after an acute stroke. This is the first score to predict the risk of delirium specifically after stroke. As it is derived from a patient's age, NIHSS and the stroke subtype, it can be calculated on the day of admission.

${ }^{1}$ Division of Clinical Neuroscience, University of Edinburgh, Edinburgh, Mid Lothian, UK; ${ }^{2}$ University of Edinburgh, Edinburgh, UK

Correspondence to Dr Stephen D J Makin, Division of Clinical Neuroscience, University of Edinburgh, Bramwell Dott Building, Western General Hospital, Crewe Road South, Edinburgh, Mid Lothian EH4 2XU, UK; stephen.makin@ed.ac.uk
This score has some limitations: first it cannot be applied to non-disabled patients, as patients discharged from hospital less than 2 days after stroke were excluded from the validation study. Second it may not be generalisable to other stroke units, as it was derived and validated in two stroke units in the Netherlands; as practice and resources may differ between countries, healthcare providers and regional and local hospitals, this score should be validated in other clinical settings before its widespread use.

The score may have a number of uses: it could identify those patients at particular risk of delirium for a future trial of preventative medication; it could aid nursing staff in ensuring that patients at risk of delirium are nursed in a easily visible space; and it could identify patients at risk so they may be screened for modifiable predisposing factors.

O'Hanlon $^{3}$ described that the effective management of delirium is a complex process requiring input at many levels, including identification of the patient at risk. For this score to reduce the mortality from delirium, it will need to be adopted as part of a wider package including improved diagnosis and treatment.

However, if this score is introduced into routine practice without resources for screening, treatment and rehabilitation, it could become merely another page in the already lengthy bundle of paperwork that staff must complete when admitting a patient to a ward, which may reduce the time spent with patients. Future research is needed to identify effective interventions that improve the outcome for patients with delirium.

Contributors SDJM wrote the editorial, and JMW revised, edited and advised on content.

\section{Competing interests None}

Provenance and peer review Commissioned; internally peer reviewed.

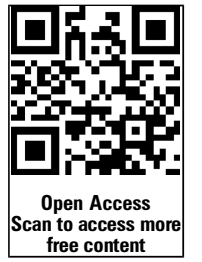

Open Access This is an Open Access article distributed in accordance with the Creative Commons Attribution Non Commercial (CC BY-NC 3.0) license, which permits others to distribute, remix, adapt, build upon this work non-commercially, and license their derivative works on different terms, provided the original work is properly cited and the use is noncommercial. See: http://creativecommons.org/licenses/ by-nc/3.0/

To cite Makin SDJ, Wardlaw J. J Neurol Neurosurg Psychiatry 2014;85:357.

Received 28 April 2013

Accepted 13 May 2013

Published Online First 13 September 2013

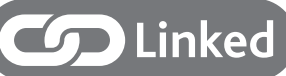

http://dx.doi.org/10.1136/jnnp-2013-304920

J Neurol Neurosurg Psychiatry 2014;85:357. doi:10.1136/jnnp-2013-305379

\section{REFERENCES}

1 Carin-Levy G, Mead GE, Nicol K, et al. Delirium in acute stroke: screening tools, incidence rates and predictors: a systematic review. I Neurol 2012;259:1590-9.

2 van Rijsbergen MW, Oldenbeuving AW, Nieuwenhuis-Mark RE, et al. Delirium in acute stroke: a predictor of subsequent cognitive impairment? A two-year follow-up study. I Neurol Sci 2011;306:138-42.

3 O'Hanlon S, O'Regan N, MacLullich AM, et al. Improving delirium care through early intervention: from bench to bedside to boardroom. I Neurol Neurosurg Psychiatry 2014;85:207-13.

4 Kakuma R, du Fort GG, Arsenault L, et al. Delirium in older emergency department patients discharged home: effect on survival. I Am Geriatr Soc 2003;51:443-50.

5 Inouye SK, Charpentier PA. Precipitating factors for delirium in hospitalized elderly persons. Predictive model and interrelationship with baseline vulnerability. JAMA 1996;275:852-7.

6 Oldenbeuving AW, de Kort PLM, van Eck van der Sluijs JF. An early prediction of delirium in the acute phase after stroke. I Neurol Neurosurg Psychiatry 2014;85:431-4. 